Research Article

\title{
Partnership Selection Involving Mixed Types of Uncertain Preferences
}

\author{
Li-Ching Ma \\ Department of Information Management, National United University, 1 Lienda, Miaoli City 36003, Taiwan
}

Correspondence should be addressed to Li-Ching Ma; lcma@nuu.edu.tw

Received 30 March 2013; Revised 2 June 2013; Accepted 3 June 2013

Academic Editor: Carlos Romero

Copyright (C) 2013 Li-Ching Ma. This is an open access article distributed under the Creative Commons Attribution License, which permits unrestricted use, distribution, and reproduction in any medium, provided the original work is properly cited.

Partnership selection is an important issue in management science. This study proposes a general model based on mixed integer programming and goal-programming analytic hierarchy process (GP-AHP) to solve partnership selection problems involving mixed types of uncertain or inconsistent preferences. The proposed approach is designed to deal with crisp, interval, step, fuzzy, or mixed comparison preferences, derive crisp priorities, and improve multiple solution problems. The degree of fulfillment of a decision maker's preferences is also taken into account. The results show that the proposed approach keeps more solution ratios within the given preferred intervals and yields less deviation. In addition, the proposed approach can treat incomplete preference matrices with flexibility in reducing the number of pairwise comparisons required and can also be conveniently developed into a decision support system.

\section{Introduction}

Partnership selection is an important issue in management science. The partnership selection problem can be formulated as a multiple criteria decision making problem [1]. Many researchers have adopted the Analytic Hierarchy Process (AHP; [2]) to solve related problems [3, 4], which uses exact values to express a decision maker's pairwise comparison judgments in complete preference matrices. However, because the information about future partners is usually incomplete and vague, a decision maker's judgments are often uncertain, inconsistent, and incomplete.

Several methods have been developed to deal with partner selection problems with uncertain preferences. For instance, Mikhailov [1] proposed a new Fuzzy Preference Programming (FPP) method based on interval pairwise comparison judgments and then used the AHP method to derive global priorities for all possible alternatives. His method can be used for deriving crisp priorities from exact or interval comparison matrices regardless of their consistency. However, the FPP method may yield multiple solution problems resulting in various ranking for partner selection. In addition, this method is unable to treat judgments with step preferences in which the degree of fulfillment is constant over the same step.

Herrera-Viedma et al. [5] developed the consistent fuzzy preference (CFP) method to construct the decision matrices of pairwise comparisons. Wang and Chen [6] applied the CFP method to partnership selection problems; their method can significantly reduce the number of pairwise comparisons since it can deal with incomplete preference matrices. The basic assumption of the CFP method is that a decision maker's judgments are consistent. However, in reality, a decision maker's pairwise judgments still contain some degree of uncertainty $[7,8]$ and inconsistency $[9,10]$.

Many researchers adopted fuzzy AHP approaches to solve problems involving fuzzy preferences [11-14]. However, most obtained fuzzy priority vector needs extra defuzzification techniques to generate a crisp solution. Yu [17] proposed a goal-programming AHP model (GP-AHP) to solve fuzzy AHP problems involving triangular, convex, and mixed concave-convex fuzzy estimates in a group decision-making environment. The GP-AHP approach can obtain a crisp solution efficiently without requiring extra defuzzification techniques. However, this approach is unable to treat judgments with step preferences. In addition, for judgments with 
interval preferences, the GP-AHP approach can be improved to keep more ratios within the given preferred intervals.

This study aims to develop a general model based on mixed integer programming and GP-AHP to solve partnership selection problems involving uncertain or inconsistent preferences. The proposed approach is designed to deal with crisp, interval, step, fuzzy, or mixed types of uncertain preferences, derive crisp priorities, and improve multiple solution problems. The degree of fulfillment of a decision maker's preferences is also taken into account. The results show that the proposed approach keeps more solution ratios within the given preferred intervals and yields less deviation. In addition, the proposed approach can also treat incomplete preference matrices, which are quite common in practice, since it is sometimes difficult for decision makers to make comparisons between certain alternatives.

This paper is organized as follows. Section 2 reviews two critical partnership selection approaches with uncertain preferences. Section 3 develops mixed integer programming models for partnership selection problems with various types of preferences. Section 4 presents three numerical examples, and Section 5 draws conclusions.

\section{Partnership Selection Approaches with Uncertain Preferences}

One common format for expressing preferences is the use of pairwise comparisons, an approach which forces one to directly choose one object over another when comparing two objects, rather than requiring the comparison of all objects simultaneously [15]. All preferences in this study are assumed to be in pairwise comparison form.

Consider the pairwise comparisons with $n$ criteria at the same level in a hierarchy $C_{1}, C_{2}, \ldots, C_{n}$. From the basis of AHP [2], the pairwise comparison of $C_{i}$ over $C_{j}$, denoted as $r_{i, j}$, is the preference specified by a decision maker as the ratio of the weights of $C_{i}$ to $C_{j}$. Let $r_{i, j}=w_{i} / w_{j}$ measure the relative dominance of $C_{i}$ over $C_{j}$ in terms of priority weights $w_{1}>0, \ldots, w_{n}>0$. Following Saaty, $r_{i, j}$ is specified as 1 to 9 numerical rate and $r_{j, i}=1 / r_{i, j}$ is assumed for all $i, j$. If a decision maker's preferences are certain, consistent, and complete, the weight of criterion can be obtained by the AHP method. Once the weight of criterion is derived, the priority of alternatives can be listed. However, a decision maker's judgments are often uncertain, inconsistent, and incomplete.

This section briefly reviews two critical partnership selection approaches with uncertain preferences: the Fuzzy Preference Programming (FPP) and the goal programming AHP (GP-AHP) method.

2.1. Fuzzy Preference Programming Method (FPP). Mikhailov [1] proposed the FPP method for partnership selection problems based on interval pairwise comparison judgments. The interval pairwise comparisons can be expressed as $r_{i, j} \epsilon$ $\left[r_{i, j}, \overline{r_{i, j}}\right]$, where $r_{i, j}$ and $\overline{r_{i, j}}$ are the lower and upper bounds of $r_{i, j}$, respectively. When the decision maker's judgments are

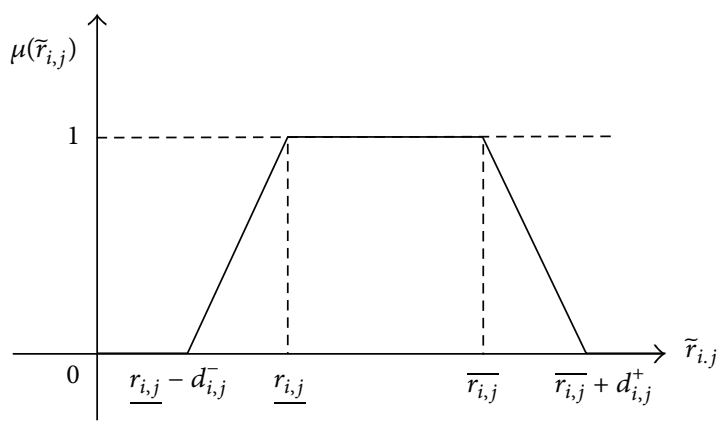

Figure 1: Membership function of the degree of fulfillment by Mikhailov [1].

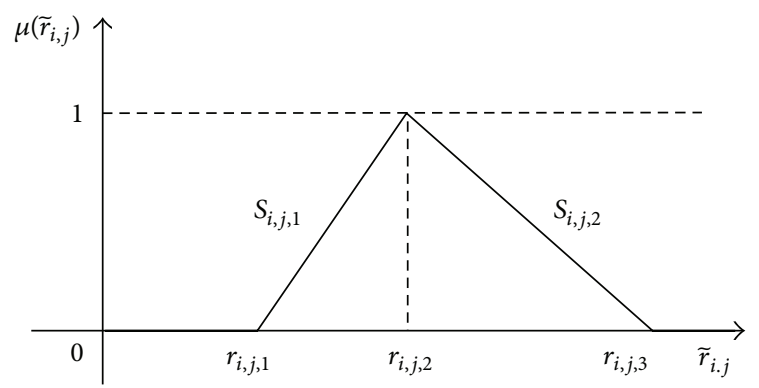

FIGURE 2: Fuzzy preference with a triangular membership function.

consistent, there are several priority vectors whose component ratios satisfy the inequalities

$$
\underline{r_{i, j}} \leq \frac{w_{i}}{w_{j}} \leq \overline{r_{i, j}}, \quad i=1,2, \ldots, n-1, j>i .
$$

However, no priority vector satisfies all interval judgments simultaneously in the inconsistent cases. Mikhailov [1] proposed a solution which approximately satisfies all judgments. It is expressed as

$$
\underline{r_{i, j}} \widetilde{\underline{\leq}} \frac{w_{i}}{w_{j}} \widetilde{\leq} \overline{r_{i, j}}, \quad i=1,2, \ldots, n-1, j>i,
$$

where $\widetilde{\leq}$ denotes the statement "fuzzy less or equal to." Fuzzy indicates approximation rather than precision. According to the concept of fuzzy set, if the ratio $w_{i} / w_{j}$ is within the interval $\left[r_{i, j}, \overline{r_{i, j}}\right]$, the degree of fulfillment is equal to one; otherwise, the degree of fulfillment should decrease up to some tolerance limits, $\overline{r_{i, j}}+d_{i, j}^{+}$and $r_{i, j}-d_{i, j}^{-}$, as shown in Figure 1.

Inequality (2) can be transformed into two fuzzy constraints:

$$
\begin{aligned}
w_{i}-w_{j} \overline{r_{i, j}} & \tilde{\leq} 0, \quad-w_{i}+w_{j} \underline{r_{i, j}} \tilde{\leq} 0, \\
i & =1,2, \ldots, n-1, \quad j>i .
\end{aligned}
$$

The previous set of fuzzy constraints is expressed as a matrix form $\mathbf{R} w \widetilde{\leq} 0$. The $k$ th row of $\mathbf{R} w \widetilde{\leq} 0$, denoted as 


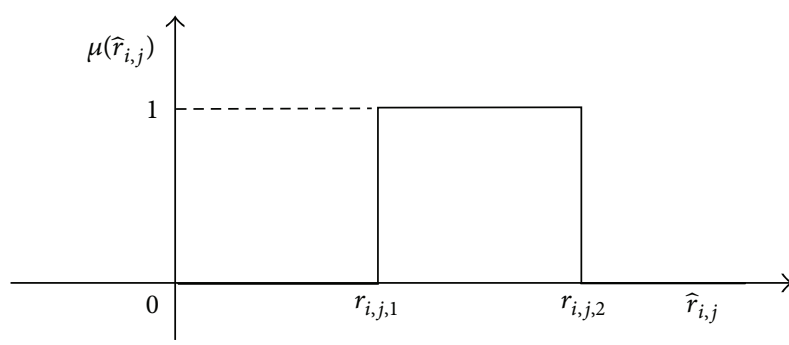

(a)

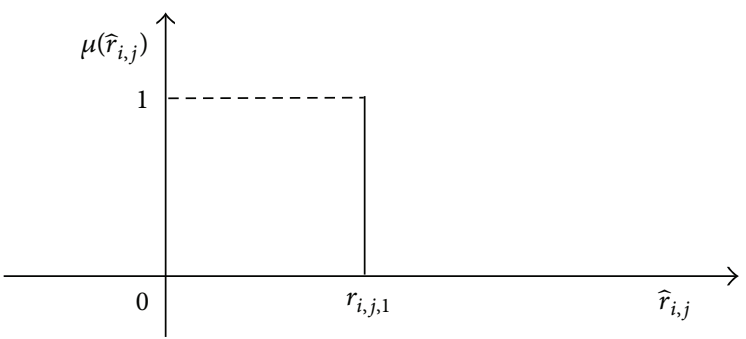

(b)

FIgURE 3: The concept diagram of interval (a) and crisp (b) preferences.

$\mathbf{R}_{k} w \widetilde{\leq} 0$, represents a fuzzy constraint and is defined by a fuzzy membership function:

$$
\mu_{k}\left(\mathbf{R}_{k} w\right)= \begin{cases}1 & \mathbf{R}_{k} w \leq 0, \\ 1-\frac{\mathbf{R}_{k} w}{d_{k}} & 0 \leq \mathbf{R}_{k} w \leq d_{k}, \\ 0 & \mathbf{R}_{k} w>d_{k},\end{cases}
$$

where if $\mathbf{R}_{k} w \widetilde{\leq} 0$ corresponds to the lower bound $r_{i, j}$, then $d_{k}=d_{i, j}^{-}$; otherwise, $d_{k}=d_{i, j}^{+}$. Using the fuzzy $\overline{\min }$-max operator method proposed by Zimmermann [16], the partnership selection problem is transformed to the following linear program:

\section{FPP model}

\section{$\operatorname{Max} \lambda$}

subject to

$$
\begin{array}{r}
d_{k} \lambda+\mathbf{R}_{k} w \leq d_{k}, \quad \forall k, \\
\sum_{i=1}^{n} w_{i}=1, \quad w_{i}>0, \quad \forall i, \\
0 \leq \lambda \leq 1 .
\end{array}
$$

This method can be used for deriving crisp priorities from exact, interval, or mixed comparison matrices. The major limitation of the FPP method is that the tolerance parameters $d_{k}$ must be chosen in advance. When the decision maker's preferences are inconsistent, different chosen $d_{k}$ may result in various solutions. On the other hand, when a decision maker's preferences are consistent, several priority vectors, whose component ratios satisfy the inequalities in the FPP model, may yield multiple solutions with various priorities. In addition, this method is unable to deal with judgments with step preferences.

2.2. GP-AHP Method. The most commonly used membership function, a triangular membership function, is illustrated as shown in Figure 2, where $r_{i, j, 1}$ and $r_{i, j, 3}$ are, respectively, the lower and upper bounds of a fuzzy preference $\widetilde{r}_{i, j}$, and $r_{i, j, 2}$ is the $\widetilde{r}_{i, j}$ value which is the most likely to occur. If there are $m$ decision makers in the group, the GP- AHP model is formulated as follows:

\section{GP-AHP model}

$$
\begin{aligned}
\text { Min } \quad & \alpha \times \text { Obj1 }- \text { Obj2 } \\
\text { Obj1 } & =\sum_{i=1}^{n} \sum_{j>i}^{n} \sum_{e=1}^{m}\left|\left(\ln w_{i}-\ln w_{j}\right)-\ln \widetilde{r}_{i, j}^{e}\right| \\
\text { Obj2 } & =\sum_{i=1}^{n} \sum_{j>i}^{n} \sum_{e=1}^{m} \mu\left(\ln \widetilde{r}_{i, j}^{e}\right)
\end{aligned}
$$

subject to

$$
\begin{aligned}
& \ln \widetilde{r}_{i, j}^{e}=\left(\left\{\mu\left(\ln \widetilde{r}_{i, j}^{e}\right)+\left(s_{i, j, 2}^{e}-s_{i, j, 1}^{e}\right) \ln r_{i, j, 2}^{e}\right.\right. \\
&\left.\left.-\left(s_{i, j, 2}^{e}-s_{i, j, 1}^{e}\right) z_{i, j}^{e}+s_{i, j, 1}^{e} \ln r_{i, j, 1}^{e}\right\}\right) \\
& \times\left(s_{i, j, 2}^{e}\right)^{-1}, \quad \forall \widetilde{r}_{i, j}^{e}, \\
& \ln \widetilde{r}_{i, j}^{e}- \ln r_{i, j, 2}^{e}+z_{i, j}^{e} \geq 0, \quad \forall \widetilde{r}_{i, j}^{e}, \\
& z_{i, j}^{e}, \widetilde{r}_{i, j}^{e} \geq 0, \quad \forall \widetilde{r}_{i, j}^{e}, \\
& w_{i} \geq 0, \quad \forall i,
\end{aligned}
$$$$
\left.\left.-\left(s_{i, j, 2}^{e}-s_{i, j, 1}^{e}\right) z_{i, j}^{e}+s_{i, j, 1}^{e} \ln r_{i, j, 1}^{e}\right\}\right)
$$

where $\widetilde{r}_{i, j}^{e}$ indicates the $e$ th decision-maker's fuzzy preference of $A_{i}$ over $A_{j}$. The deviation variable, $z_{i, j}^{e}$, is used to treat the absolute term. The triangular membership, $\mu\left(\ln \left(\widetilde{r}_{i, j}^{e}\right)\right)$, is a function of $\ln \left(\widetilde{r}_{i, j}^{e}\right)$, where $\ln \left(r_{i, j, 1}^{e}\right), \ln \left(r_{i, j, 2}^{e}\right)$, and $\ln \left(r_{i, j, 3}^{e}\right)$ are lower, middle, and upper values of $\ln \left(\widetilde{r}_{i, j}^{e}\right)$. The slopes of the two line segments in the triangular membership function, $s_{i, j, 1}^{e}$ and $s_{i, j, 2}^{e}$, are given by

$$
\begin{gathered}
s_{i, j, 1}^{e}=\frac{\mu\left(\ln \left(r_{i, j, 2}^{e}\right)\right)-\mu\left(\ln \left(r_{i, j, 1}^{e}\right)\right)}{\ln \left(r_{i, j, 2}^{e}\right)-\ln \left(r_{i, j, 1}^{e}\right)}, \\
s_{i, j, 2}^{e}=\frac{\mu\left(\ln \left(r_{i, j, 3}^{e}\right)\right)-\mu\left(\ln \left(r_{i, j, 2}^{e}\right)\right)}{\ln \left(r_{i, j, 3}^{e}\right)-\ln \left(r_{i, j, 2}^{e}\right)} .
\end{gathered}
$$

The trade-off weighting value $\alpha$ is calculated by $\alpha=(n \times$ $m) /\left|M^{1}-M^{0}\right|$, where $M^{1}$ and $M^{0}$ are obtained solutions by assuming that each $\mu\left(\ln \left(\widetilde{r}_{i, j}^{e}\right)\right)$ equals one and zero, respectively. 
Yu [17] applied a linearization technique to solve fuzzy AHP problems effectively. However, Yu's approach to interval preferences can be improved. For instance, given an interval preference $2 \leq r_{1,4} \leq 5$, only one constraint $\ln (2) \leq \ln r_{1,4} \leq$ $\ln (5)$ is added into Yu's model. This model can be improved to increase the possibility that final ratios are actually located in the given preferred intervals. In addition, Yu's approach is unable to treat judgments with step preferences.

This study aims to develop a general model to solve partnership selection problems involving various types of uncertain preferences and improve the limitations of the previous two methods.

\section{Multiobjective Programming Models for Various Types of Preferences}

A general model is proposed to deal with exact, interval, step, fuzzy, or mixed comparison matrices for partnership selection problems regardless of inconsistencies. First denote $\widehat{r}_{i, j}$ as the uncertain preference of $A_{i}$ over $A_{j}$, and let $F, V, C, S$ be the set of fuzzy, interval, crisp, and step preferences, respectively. This study assumes that $\widehat{r}_{i, j} \in\{F, V, C, S\}$. Models for fuzzy, interval, crisp, and step preferences are developed first. A general model with mixed preferences is constructed last.

3.1. Fuzzy Preferences. A decision maker may prefer to specify fuzzy preferences (i.e., $\widehat{r}_{i, j} \in F$, also denoted as $\widetilde{r}_{i, j}$ commonly). Fuzzy preferences represent that a decision maker's judgments are approximate rather than precise. The proposed model for fuzzy preferences is based on the work of $\mathrm{Yu}$ [17]. Denote $\mu\left(\widehat{r}_{i, j}\right)$ as the membership function of a fuzzy preference $\widehat{r}_{i, j} \in F$. A fuzzy AHP problem can be expressed in the following multiobjective programming form:

$$
\begin{aligned}
& \text { Min } \quad \text { Obj1 }=\sum_{\widehat{r}_{i, j} \in F}\left|\frac{w_{i}}{w_{j}}-\widehat{r}_{i, j}\right| \\
& \text { Max } \quad \text { Obj2 }=\sum_{\widehat{r}_{i, j} \in F} \mu\left(\widehat{r}_{i, j}\right) \\
& \text { subject to } \quad \sum_{i=1}^{n} w_{i}=1, \\
& \widehat{r}_{i, j} \geq 0, \quad \forall \widehat{r}_{i, j} \in F, \\
& w_{i} \geq 0, \quad \forall i .
\end{aligned}
$$

The first objective is to minimize the sum of deviations resulting from approximation, and the second objective is to maximize the sum of membership functions of $\widehat{r}_{i, j}$, which indicates the fulfillment of the decision maker's preferences. This model is in the form of goalprogramming [18], which can be solved by the weights method [19] to optimize both objectives jointly.

A triangular membership function is illustrated and denoted as $\widehat{r}_{i, j}=\left(r_{i, j, 1}, r_{i, j, 2}, r_{i, j, 3}\right), \widehat{r}_{i, j} \in F$. According to the studies of $\mathrm{Yu}$ [17] and $\mathrm{Ma}$ and $\mathrm{Li}$ [20], a piecewise linear function of $\ln \left(\widehat{r}_{i, j}\right)$ can be expressed as

$$
\begin{aligned}
\mu\left(\ln \left(\widehat{r}_{i, j}\right)\right)= & s_{i, j, 1} \times\left(\ln \left(\widehat{r}_{i, j}\right)-\ln \left(r_{i, j, 1}\right)\right)+\frac{\left(s_{i, j, 2}-s_{i, j, 1}\right)}{2} \\
& \times\left(\left|\ln \left(\widehat{r}_{i, j}\right)-\ln \left(r_{i, j, 2}\right)\right|+\ln \left(\widehat{r}_{i, j}\right)-\ln \left(r_{i, j, 2}\right)\right),
\end{aligned}
$$

where $s_{i, j, 1}=\left(\mu\left(\ln \left(r_{i, j, 2}\right)\right)-\mu\left(\ln \left(r_{i, j, 1}\right)\right) /\left(\ln \left(r_{i, j, 2}\right)-\ln \left(r_{i, j, 1}\right)\right)\right.$ and $s_{i, j, 2}=\left(\mu\left(\ln \left(r_{i, j, 3}\right)\right)-\mu\left(\ln \left(r_{i, j, 2}\right)\right)\right) /\left(\left(\ln \left(r_{i, j, 3}\right)-\ln \left(r_{i, j, 2}\right)\right)\right.$. $|o|$ is the absolute value of $o$.

After using the logarithms, the multi-objective programming model can be transferred into a linear program as follows.

Model 1: Multiobjective Programming Fuzzy Preference Model (MPFP). Consider

$$
\begin{aligned}
& \text { Min } \quad \text { Obj } 1=\sum_{\vec{r}_{i, j} \in F}\left(\ln \left(w_{i}\right)-\ln \left(w_{j}\right)\right. \\
& \left.-\ln \left(\widehat{r}_{i, j}\right)+2 z_{i, j}\right) \\
& \operatorname{Max} \quad \mathrm{Obj} 2=\sum_{\widehat{r}_{i, j} \in F} \mu\left(\ln \left(\widehat{r}_{i, j}\right)\right) \\
& \text { subject to } \ln \left(w_{i}\right)-\ln \left(w_{j}\right)-\ln \left(\widehat{r}_{i, j}\right)+z_{i, j} \geq 0 \text {, } \\
& \forall \widehat{r}_{i, j} \in F, \\
& z_{i, j} \geq 0, \quad \forall \widehat{r}_{i, j} \in F, \\
& \ln (0.01) \leq \ln \left(w_{i}\right) \leq \ln (1), \quad \forall i, \\
& \mu\left(\ln \left(\widehat{r}_{i, j}\right)\right)=s_{i, j, 1} \times\left(\ln \left(\widehat{r}_{i, j}\right)-\ln \left(r_{i, j, 1}\right)\right) \\
& +\left(s_{i, j, 2}-s_{i, j, 1}\right) \\
& \times\left(\ln \left(\widehat{r}_{i, j}\right)-\ln \left(r_{i, j, 2}\right)+x_{i, j}\right), \\
& \forall \widehat{r}_{i, j} \in F, \\
& \ln \left(\widehat{r}_{i, j}\right)-\ln \left(r_{i, j, 2}\right)+x_{i, j} \geq 0, \quad \forall \widehat{r}_{i, j} \in F, \\
& x_{i, j} \geq 0, \quad \forall \widehat{r}_{i, j} \in F .
\end{aligned}
$$

In order to linearize the absolute term in Objl, constraints (15) and (16) are added into the model. Expression (17) is used to set the range of weight $w_{i}$ between 0.01 and 1 . Expression (20) is derived from Expression (13). Expressions (19) and (20) are based on $\mathrm{Yu}$ [17].

3.2. Constant Interval Preferences. A decision maker may provide constant interval judgments $\widehat{r}_{i, j} \in V$ and $\widehat{r}_{i, j}=$ $\left[r_{i, j, 1}, r_{i, j, 2}\right]$, where $r_{i, j, 1}=r_{i, j}$ and $r_{i, j, 2}=\overline{r_{i, j}}$ indicate the lower and upper bounds, respectively, as shown in Figure 3. In 


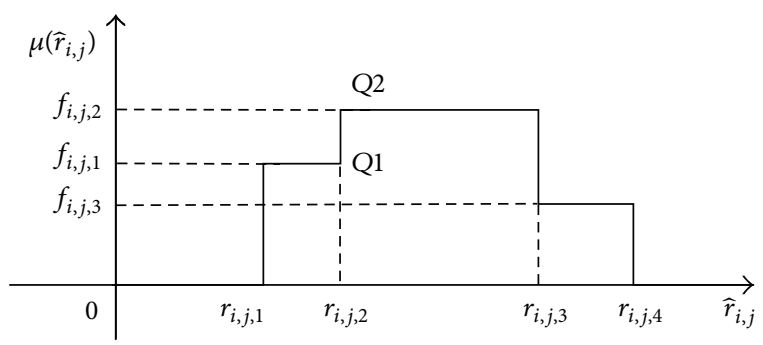

FIGURE 4: The concept diagram of a three-step preference.

order to integrate different types of preferences, the objective functions of all proposed models are constructed similar to those of MPFP model. This study tries to use the function $\mu\left(\widehat{r}_{i, j}\right)$ to represent the fulfillment of the decision maker's interval preferences. If the optimal preference ratio $w_{i}^{*} / w_{j}^{*}$ is located in the given preferred interval (i.e., $r_{i, j, 1} \leq w_{i}^{*} / w_{j}^{*} \leq$ $\left.r_{i, j, 2}\right)$, then $\mu\left(\widehat{r}_{i, j}\right)=1$; otherwise, $\mu\left(\widehat{r}_{i, j}\right)=0$. A binary variable $b_{i, j, 0}$ is used to indicate whether the optimal preference ratio $w_{i}^{*} / w_{j}^{*}$ is in the interval $\left[r_{i, j, 1}, r_{i, j, 2}\right]$ or not. A mixed integer programming interval preference model (MPVP) can be expressed as follows.

Model 2: Multiobjective Programming Interval Preference Model (MPVP). Consider

$$
\begin{array}{r}
\operatorname{Min} \text { Obj1 }=\sum_{\widehat{r}_{i, j} \in V}\left(\ln \left(w_{i}\right)-\ln \left(w_{j}\right)\right. \\
\left.-\ln \left(\widehat{r}_{i, j}\right)+2 z_{i, j}\right) \\
\operatorname{Max} \quad \text { Obj2 }=\sum_{\hat{r}_{i, j} \in V} \mu\left(\ln \left(\widehat{r}_{i, j}\right)\right)
\end{array}
$$

subject to $\quad(15) \sim(17), \quad \forall \widehat{r}_{i, j} \in V$,

$$
\begin{aligned}
& \ln \left(r_{i, j, 1}\right)-M\left(1-b_{i, j, 0}\right) \\
& \quad \leq \ln \left(w_{i}\right)-\ln \left(w_{j}\right) \\
& \quad \leq \ln \left(r_{i, j, 2}\right)+M\left(1-b_{i, j, 0}\right), \quad \forall \widehat{r}_{i, j} \in V,
\end{aligned}
$$

$$
\begin{array}{r}
1+\left(b_{i, j, 0}-1\right) \leq \mu\left(\ln \left(\widehat{r}_{i, j}\right)\right) \leq 1+\left(b_{i, j, 0}-1\right) \\
\forall \widehat{r}_{i, j} \in V,
\end{array}
$$

$$
\begin{aligned}
& \ln \left(r_{i, j, 1}\right)-M b_{i, j, 0} \leq \ln \left(\widehat{r}_{i, j}\right) \\
& \leq \ln \left(r_{i, j, 2}\right)+M b_{i, j, 0}, \\
& \forall \widehat{r}_{i, j} \in V
\end{aligned}
$$$$
b_{i, j, 0} \in\{0,1\}, \quad \forall \widehat{r}_{i, j} \in V,
$$

$M$ is a large value.

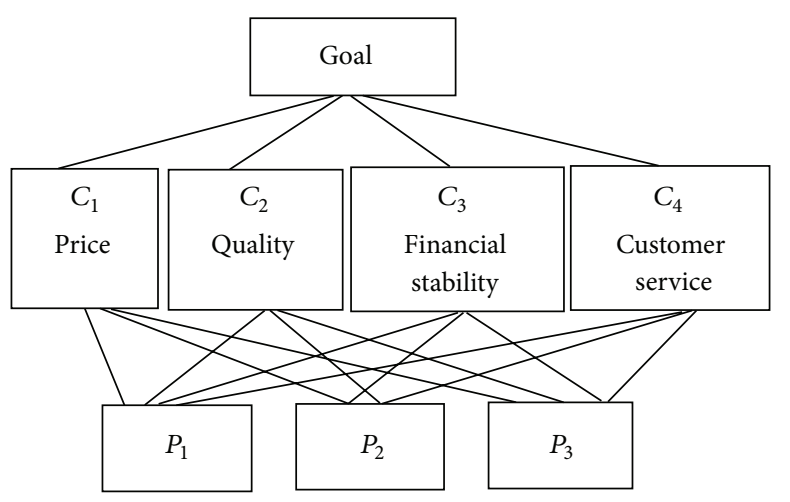

FIGURE 5: Hierarchy structure of Example 1.

The objective functions of the MPVP model are similar to those of the MPFP model. From Expressions (22)-(24), if $b_{i, j, 0}=1, \ln \left(r_{i, j, 1}\right) \leq \ln \left(w_{i}\right)-\ln \left(w_{j}\right) \leq \ln \left(r_{i, j, 2}\right)$ and $\mu\left(\ln \left(\widehat{r}_{i, j}\right)\right)=1$; otherwise, if $b_{i, j, 0}=0, \mu\left(\ln \left(\widehat{r}_{i, j}\right)\right) \stackrel{=}{=} 0$ and $\ln \left(r_{i, j, 1}\right) \leq \ln \left(\widehat{r}_{i, j}\right) \leq \ln \left(r_{i, j, 2}\right)$. So, if the final preference ratio $w_{i}^{*} / w_{j}^{*}$ is located in the given interval, the decision maker's preference is thoroughly fulfilled; otherwise, the model will find the priority weight ratio approaching $\widehat{r}_{i, j}$ as closely as possible. Because Obj2 is to maximize the sum of $\mu\left(\ln \left(\widehat{r}_{i, j}\right)\right)$, this model can keep as many preference ratios in the given interval as possible.

Yu's approach [17] is a slope-based approach, as shown in Expressions (7) and (11). The slope of every line segment has to be calculated in advance. The proposed approach is a mixed integer programming approach. For constant interval preferences, a binary variable $b_{i, j, 0}$ is employed for each $\widehat{r}_{i, j}$ to keep as many preference ratios $w_{i}^{*} / w_{j}^{*}$ located in the given interval as possible; that is, the number of solution ratios which are finally located in the decision maker's preference range is maximized. Therefore, the proposed model can keep more preference ratios in the given interval than Yu's [17] approach.

3.3. Crisp Preferences. A crisp preference can be considered as a special case of interval preference with equal lower and upper bounds; that is, $r_{i, j, 2}=r_{i, j, 1}$, for all $\widehat{r}_{i, j} \in C$. If the optimal preference ratio $w_{i}^{*} / w_{j}^{*}=r_{i, j, 1}$, then $\mu\left(\widehat{r}_{i, j}\right)=1$; otherwise, $\mu\left(\widehat{r}_{i, j}\right)=0$, as shown in Figure 3 . The mixedinteger programming crisp preference model (MPCP) can be constructed as follows.

Model 3: Multiobjective Programming Crisp Preference Model (MPCP). Consider

$$
\begin{aligned}
& \text { Min } \quad \text { Obj1 }=\sum_{r_{i, j} \in C}\left(\ln \left(w_{i}\right)-\ln \left(w_{j}\right)\right. \\
& \left.-\ln \left(\widehat{r}_{i, j}\right)+2 z_{i, j}\right) \\
& \operatorname{Max} \operatorname{Obj} 2=\sum_{\hat{r}_{i, j} \in C} \mu\left(\ln \left(\widehat{r}_{i, j}\right)\right)
\end{aligned}
$$

subject to $\quad(15) \sim(17),(22) \sim(25), \quad \forall \widetilde{r}_{i, j} \in C$. 
3.4. Step Preferences. A decision maker may specify multistep preferences in which the degree of fulfillment is constant over the same step. A q-step preference function is denoted as $\widehat{r}_{i, j}=$ $\left[r_{i, j, 1}, r_{i, j, 2}, \ldots, r_{i, j, q+1}: f_{i, j, 1}, f_{i, j, 2}, \ldots, f_{i, j, q}\right]$, for all $\widehat{r}_{i, j} \in S$, and formulated as follows:

$$
\mu\left(\widehat{r}_{i, j}\right)=\left\{\begin{array}{lc}
f_{i, j, 1} & \text { for } r_{i, j 1} \leq \widehat{r}_{i, j} \leq r_{i, j, 2} \\
f_{i, j, 2} & \text { for } r_{i, j 2} \leq \widehat{r}_{i, j} \leq r_{i, j, 3} \\
\vdots & \vdots \\
f_{i, j, q} & \text { for } r_{i, j q} \leq \widehat{r}_{i, j} \leq r_{i, j, q+1},
\end{array} \quad \forall \widehat{r}_{i, j} \in S,\right.
$$

where $f_{i, j, q}$ denotes the degree of fulfillment for the $q$ th step, which is restricted in $[0,1]$.

For instance, a three-step preference is shown in Figure 4, where if $r_{i, j, 1} \leq \widehat{r}_{i, j} \leq r_{i, j, 2}, \mu\left(\widehat{r}_{i, j}\right)=f_{i, j, 1}$; if $r_{i, j, 2} \leq \widehat{r}_{i, j} \leq r_{i, j, 3}$, $\mu\left(\widehat{r}_{i, j}\right)=f_{i, j, 2}$; if $r_{i, j, 3} \leq \widehat{r}_{i, j} \leq r_{i, j, 4}, \mu\left(\widehat{r}_{i, j}\right)=f_{i, j, 3}$. This threestep preference is denoted as $\hat{r}_{i, j}=\left[r_{i, j, 1}, r_{i, j, 2}, r_{i, j, 3}, r_{i, j, 4}\right.$ : $\left.f_{i, j, 1}, f_{i, j, 2}, f_{i, j, 3}\right]$. Two $0 / 1$ variables $b_{i, j, 0}$ and $b_{i, j, 1}$ are used to delineate $\mu\left(\hat{r}_{i, j}\right)$ into the following 4 cases:

(i) $b_{i, j, 0}=0$ and $b_{i, j, 1}=1$ : if $r_{i, j, 1} \leq w_{i}^{*} / w_{j}^{*} \leq r_{i, j, 2}$, then $\mu\left(\widehat{r}_{i, j}\right)=f_{i, j, 1}$;

(ii) $b_{i, j, 0}=1$ and $b_{i, j, 1}=0$ : if $r_{i, j, 2} \leq w_{i}^{*} / w_{j}^{*} \leq r_{i, j, 3}$, then $\mu\left(\widehat{r}_{i, j}\right)=f_{i, j, 2}$

(iii) $b_{i, j, 0}=1$ and $b_{i, j, 1}=1$ : if $r_{i, j, 3} \leq w_{i}^{*} / w_{j}^{*} \leq r_{i, j, 4}$, then $\mu\left(\widehat{r}_{i, j}\right)=f_{i, j, 3}$

(iv) $b_{i, j, 0}=0$ and $b_{i, j, 1}=0$ : if $w_{i}^{*} / w_{j}^{*}<r_{i, j, 1}$ or $w_{i}^{*} / w_{j}^{*}>$ $r_{i, j, 4}$, then $\mu\left(\widehat{r}_{i, j}\right)=0$. lows.

A three-step preference model can be expressed as fol-

Model 4: Multiobjective Programming Step Preference Model (MPSP). Consider

$$
\begin{array}{r}
\text { Min Obj1 }=\sum_{\hat{r}_{i, j} \in S}\left(\ln \left(w_{i}\right)-\ln \left(w_{j}\right)\right. \\
\left.-\ln \left(\widehat{r}_{i, j}\right)+2 z_{i, j}\right)
\end{array}
$$$$
\operatorname{Max} \quad \operatorname{Obj} 2=\sum_{\widehat{r}_{i, j} \in S} \mu\left(\ln \left(\widehat{r}_{i, j}\right)\right)
$$

subject to $\quad(15) \sim(17), \quad \forall \widehat{r}_{i, j} \in S$

$$
\begin{array}{r}
\ln \left(r_{i, j, 1}\right)-M\left(1+b_{i, j, 0}-b_{i, j, 1}\right) \\
\leq \ln \left(w_{i}\right)-\ln \left(w_{j}\right) \\
\leq \ln \left(r_{i, j, 2}\right)+M\left(1+b_{i, j, 0}-b_{i, j, 1}\right), \\
\forall \widehat{r}_{i, j} \in S,
\end{array}
$$

$$
\begin{aligned}
& \ln \left(r_{i, j, 2}\right)-M\left(1-b_{i, j, 0}+b_{i, j, 1}\right) \\
& \leq \ln \left(w_{i}\right)-\ln \left(w_{j}\right) \\
& \leq \ln \left(r_{i, j, 3}\right)+M\left(1-b_{i, j, 0}+b_{i, j, 1}\right), \\
& \forall \widehat{r}_{i, j} \in S,
\end{aligned}
$$

$$
\begin{array}{r}
\ln \left(r_{i, j, 3}\right)-M\left(2-b_{i, j, 0}-b_{i, j, 1}\right) \\
\leq \ln \left(w_{i}\right)-\ln \left(w_{j}\right) \\
\leq \ln \left(r_{i, j, 4}\right)+M\left(2-b_{i, j, 0}-b_{i, j, 1}\right), \\
\forall \widehat{r}_{i, j} \in S,
\end{array}
$$

$$
\begin{array}{r}
\ln \left(r_{i, j, 1}\right)-M\left(b_{i, j, 0}+b_{i, j, 1}\right) \\
\leq \ln \left(\widehat{r}_{i, j}\right) \\
\leq \ln \left(r_{i, j, 4}\right)+M\left(b_{i, j, 0}+b_{i, j, 1}\right), \\
\forall \widehat{r}_{i, j} \in S,
\end{array}
$$$$
f_{i, j, 1}-M\left(1+b_{i, j, 0}-b_{i, j, 1}\right)
$$$$
\leq \mu\left(\ln \left(\widehat{r}_{i, j}\right)\right)
$$$$
\leq f_{i, j, 1}+M\left(1+b_{i, j, 0}-b_{i, j, 1}\right) \text {, }
$$

$$
\forall \widehat{r}_{i, j} \in S,
$$$$
f_{i, j, 2}-M\left(1-b_{i, j, 0}+b_{i, j, 1}\right)
$$$$
\leq \mu\left(\ln \left(\widehat{r}_{i, j}\right)\right)
$$$$
\leq f_{i, j, 2}+M\left(1-b_{i, j, 0}+b_{i, j, 1}\right) \text {, }
$$$$
\forall \widehat{r}_{i, j} \in S,
$$

$$
\begin{aligned}
& f_{i, j, 3}- M\left(2-b_{i, j, 0}-b_{i, j, 1}\right) \\
& \leq \mu\left(\ln \left(\widehat{r}_{i, j}\right)\right) \\
& \leq f_{i, j, 3}+M\left(2-b_{i, j, 0}-b_{i, j, 1}\right), \\
& \forall \widehat{r}_{i, j} \in S,
\end{aligned}
$$


TABLE 1: Interval pairwise comparisons of criteria (Example 1).

\begin{tabular}{lcccc}
\hline Goal & $C_{1}$ & $C_{2}$ & $C_{3}$ & $C_{4}$ \\
\hline$C_{1}$ & 1 & $2-3$ & $3-5$ & $4-7$ \\
$C_{2}$ & & 1 & $1-2$ & $3-4$ \\
$C_{3}$ & & 1 & $2-4$ \\
$C_{4}$ & & & & 1 \\
\hline
\end{tabular}

TABLE 2: Interval pairwise comparisons of alternatives (Example 1).

\begin{tabular}{cccc}
\hline & $P_{1}$ & $P_{2}$ & $P_{3}$ \\
\hline$C_{1}:$ Price & & & \\
$P_{1}$ & 1 & $1.0-1.1$ & $1.2-1.3$ \\
$P_{2}$ & & 1 & $1.1-1.2$ \\
$P_{3}$ & & & 1 \\
$C_{2}:$ Quality & & & \\
$P_{1}$ & 1 & & \\
$P_{2}$ & $1.4-1.8$ & 1 & $1.2-1.4$ \\
$P_{3}$ & $1.3-1.5$ & & 1 \\
$C_{3}:$ Financial stability & & & \\
$P_{1}$ & 1 & & $4.0-5.0$ \\
$P_{2}$ & $2.0-3.0$ & 1 & $3.0-5.0$ \\
$P_{3}$ & & & 1 \\
$C_{4}:$ Customer service & & & \\
$P_{1}$ & 1 & $3.0-6.0$ & $8.0-13.0$ \\
$P_{2}$ & & 1 & $5.0-9.0$ \\
$P_{3}$ & & & 1 \\
\hline
\end{tabular}

$$
\begin{aligned}
& M\left(b_{i, j, 0}+b_{i, j, 1}\right) \\
& \quad \leq \mu\left(\ln \left(\widehat{r}_{i, j}\right)\right), \\
& \quad \leq M\left(b_{i, j, 0}+b_{i, j, 1}\right) \quad \forall \widehat{r}_{i, j} \in S, \\
& b_{i, j, 0}, b_{i, j, 1} \in\{0,1\}, \quad \forall \widehat{r}_{i, j} \in S,
\end{aligned}
$$

$M$ is a large value.

Case (i) is represented in Expressions (29) and (33) with $b_{i, j, 0}=0$ and $b_{i, j, 1}=1$. Case (ii) is shown in Expressions (30) and (34) with $b_{i, j, 0}=1$ and $b_{i, j, 1}=0$. Case (iii) is described in Expressions (31) and (35) with $b_{i, j, 0}=1$ and $b_{i, j, 1}=1$. Case (iv) is exhibited in Expressions (32) and (36) with $b_{i, j, 0}=0$ and $b_{i, j, 1}=0$. In case (iv), following Obj1, $w_{i}^{*} / w_{j}^{*}$ will be as close to $\widetilde{r}_{i, j}$ as possible, given $r_{i, j, 1} \leq \widehat{r}_{i, j} \leq r_{i, j, 4}$. In order to integrate different types of preferences, the objective functions of this MPSP model are designed similar to those of MPFP model.

Yu's approach [17] cannot treat problems involving step preferences. As mentioned before, Yu's approach is a slopebased approach. The slope of every line segment has to be calculated in advance as listed in Expression (11). However, for step preferences, the slopes of some line segments cannot be calculated. For instance, the slope of line segment between points Q1 and Q2 in Figure 4 is infeasible. The proposed approach for step preferences is based on mixed integer programming rather than slope-based approach. Two binary variables $b_{i, j, 0}$ and $b_{i, j, 1}$ for each $\tilde{r}_{i, j}$ are designed to solve problems with step preferences as listed in Expressions (29)-(37).

3.5. Mixed Preferences. In order to aggregate different types of preferences, the objective functions of Models 1-4 are developed in the similar way in this study. Models for interval, crisp, and step preferences are constructed as a compatible form with fuzzy preferences. If a decision maker's pairwise comparison matrix contains fuzzy, interval, crisp, and step preferences, a general mixed preference model can be formulated based on Models 1,2,3, and 4 as follows.

Model 5: Multiobjective Programming Mixed Preference Model (MPMP). Consider

$$
\begin{array}{cl}
\text { Min } \quad \text { Obj } 1=\sum_{\widehat{r}_{i, j} \in F \cup V \cup C \cup S}\left(\ln \left(w_{i}\right)-\ln \left(w_{j}\right)\right. & \left.-\ln \left(\widehat{r}_{i, j}\right)+2 z_{i, j}\right) \\
\text { Max } \quad \text { Obj2 }=\sum_{\hat{r}_{i, j} \in F \cup V \cup C \cup S} \mu\left(\ln \left(\widehat{r}_{i, j}\right)\right)
\end{array}
$$

The proposed models try to minimize Obj1, which implies that $w_{i}^{*} / w_{j}^{*}$ is as close to $\widehat{r}_{i, j}$ as possible, and to maximize Obj2, which indicates that the extent of decision makers' preferences is fulfilled as thoroughly as possible. The proposed models are multiobjective linear optimization problems, which can be solved using many techniques to get a global optimum. One of the commonly used methods is formulated as follows:

$$
\begin{aligned}
\text { Min } & \alpha \times \text { Obj1 }- \text { Obj2 } \\
\text { subject to } & \text { all other constraints are } \\
& \text { in the proposed models, }
\end{aligned}
$$

where $\alpha$ is a given weight variable reflecting the relative importance between Obj1 and Obj2. Because Obj1 is regarded as the most important objective in this study, $\alpha=1000000$ is given. By dividing the sum of weights, all the weight $w_{i}$ can be normalized to the range $[0,1]$ and $\sum_{i=1}^{n} w_{i}=1$. The proposed models can be easily solved by commercial software such as Lingo. 
TABLE 3: Decision table of FPP, CFP, and proposed MPFP methods (Example 1).

\begin{tabular}{|c|c|c|c|c|c|c|c|c|c|c|c|c|c|c|c|}
\hline & \multicolumn{3}{|c|}{ Price $\left(w_{1}\right)$} & \multicolumn{3}{|c|}{ Quality $\left(w_{2}\right)$} & \multicolumn{3}{|c|}{ Finance $\left(w_{3}\right)$} & \multicolumn{3}{|c|}{ Service $\left(w_{4}\right)$} & \multicolumn{3}{|c|}{ Global priority } \\
\hline & FPP & CFP & MPFP & FPP & CFP & MPFP & FPP & CFP & MPFP & FPP & CFP & MPFP & FPP & CFP & MPFP \\
\hline & 0.504 & 0.370 & 0.506 & 0.259 & 0.276 & 0.253 & 0.163 & 0.234 & 0.169 & 0.074 & 0.120 & 0.072 & & & \\
\hline$P_{1}$ & 0.364 & 0.345 & 0.368 & 0.244 & 0.299 & 0.238 & 0.325 & 0.311 & 0.294 & 0.705 & 0.492 & 0.709 & 0.352 & 0.342 & 0.347 \\
\hline$P_{2}$ & 0.342 & 0.338 & 0.338 & 0.421 & 0.370 & 0.429 & 0.575 & 0.450 & 0.588 & 0.242 & 0.347 & 0.236 & 0.393 & 0.374 & 0.396 \\
\hline$P_{3}$ & 0.294 & 0.317 & 0.294 & 0.335 & 0.331 & 0.333 & 0.100 & 0.239 & 0.118 & 0.053 & 0.161 & 0.055 & 0.255 & 0.284 & 0.257 \\
\hline
\end{tabular}

TABLE 4: Solution matrix of criteria for FPP, CFP, and MPFP methods (Example 1).

\begin{tabular}{|c|c|c|c|c|c|c|c|c|c|c|c|c|c|c|c|c|}
\hline \multirow{2}{*}{ Criteria } & \multicolumn{4}{|c|}{$C_{1}$} & \multicolumn{4}{|c|}{$C_{2}$} & \multicolumn{4}{|c|}{$C_{3}$} & \multicolumn{4}{|c|}{$C_{4}$} \\
\hline & Data & FPP & CFP & MPFP & Data & FPP & CFP & MPFP & Data & FPP & CFP & MPFP & Data & FPP & CFP & MPFP \\
\hline$C_{1}$ & & & 1 & & $2-3$ & $1.946^{*}$ & $1.341^{*}$ & 2.000 & $3-5$ & 3.092 & $1.581^{*}$ & 3.000 & $4-7$ & 6.811 & $3.083^{*}$ & 7.000 \\
\hline$C_{2}$ & & & & & & & 1 & & $1-2$ & 1.589 & 1.179 & 1.500 & $3-4$ & 3.500 & 2.300 & 3.500 \\
\hline$C_{3}$ & & & & & & & & & & & 1 & & $2-4$ & 2.203 & $1.950^{*}$ & 2.333 \\
\hline $\mathrm{C}_{4}$ & & & & & & & & & & & & & & & 1 & \\
\hline
\end{tabular}

The value marked with "*” indicates that this value is out of the decision maker's preference range.

TABLE 5: Solution matrix of alternatives for $C_{1}$ (Example 1).

\begin{tabular}{|c|c|c|c|c|c|c|c|c|c|c|c|c|}
\hline \multirow{2}{*}{$C_{1}$ : Price } & \multicolumn{4}{|c|}{$P_{1}$} & \multicolumn{4}{|c|}{$P_{2}$} & \multicolumn{4}{|c|}{$P_{3}$} \\
\hline & Data & FPP & CFP & MPFP & Data & FPP & CFP & MPFP & Data & FPP & CFP & MPFP \\
\hline$P_{1}$ & & & 1 & & $1.0-1.1$ & 1.064 & 1.021 & 1.087 & $1.2-1.3$ & 1.238 & $1.088^{*}$ & 1.250 \\
\hline$P_{2}$ & & & & & \multirow{2}{*}{\multicolumn{4}{|c|}{1}} & $1.1-1.2$ & 1.163 & $1.066^{*}$ & 1.150 \\
\hline$P_{3}$ & & & & & & & & & \multicolumn{4}{|c|}{1} \\
\hline
\end{tabular}

TABLE 6: Solution matrix of alternatives for $C_{2}$ (Example 1).

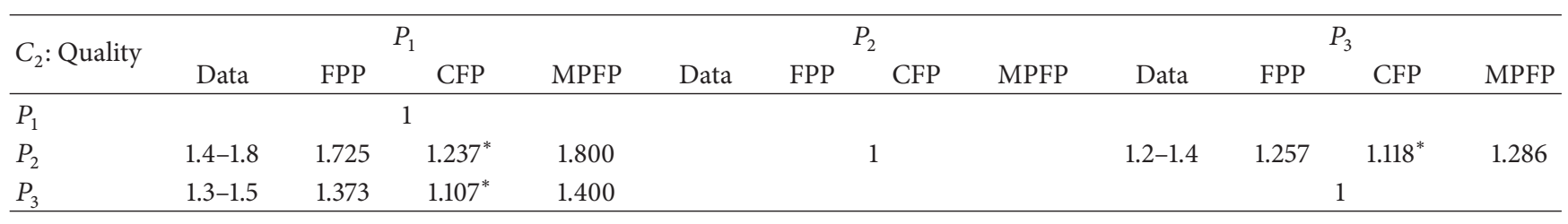

In order to compare the performance of different approaches, the absolute difference in the solution ratio $r_{i, j}$ from the original given ranges $\left[r_{i, j}, \overline{r_{i, j}}\right]$ can be defined as

$$
v_{i, j}= \begin{cases}r_{i, j}-\overline{r_{i, j}}, & \text { if } r_{i, j}>\overline{r_{i, j}} \\ r_{i, j}-r_{i, j}, & \text { if } r_{i, j}<\underline{r_{i, j}} \\ 0, & \text { if } \underline{r_{i, j}}<\overline{r_{i, j}}<\overline{r_{i, j}} .\end{cases}
$$

The smaller the $v_{i, j}$, the closer the approach to the decision maker's preference. Âll absolute differences $v_{i, j}$ in a matrix can be calculated to obtain the total absolute differences. The performance of different approaches can be measured by (i) the number of solution ratios which are out of the decision maker's preference range, (ii) the value of the total absolute difference, and (iii) degree of fulfillment of the decision maker's preferences.

\section{Illustrative Examples}

Three examples are illustrated in this section. The first example uses three different fuzzy approaches to solve partnership selection problem. The second example illustrates how to solve a mixed type of pairwise comparison matrix with fuzzy, crisp, and interval preferences. Finally, a step preference is added into the third example.

Example 1. This example is about a partnership selection problem in the formation of new virtual enterprises [1]. The hierarchical structure of the problem is shown in Figure 5. The goal of this problem is to choose a partner to supply a specific product. Four main criteria are taken into account: the price of the product $\left(C_{1}\right)$, the quality of the product $\left(C_{2}\right)$, the financial stability of the partner $\left(C_{3}\right)$, and the customer service of the partner $\left(C_{4}\right)$. There are three alternative partners $P_{1}, P_{2}$, and $P_{3}$. The interval pairwise comparisons of all criteria and alternatives are listed in Tables 1 and 2 . Since the pairwise comparison matrix is reciprocal, only the elements greater or equal to 1 are presented. 
TABLE 7: Solution matrix of alternatives for $C_{3}$ (Example 1).

\begin{tabular}{|c|c|c|c|c|c|c|c|c|c|c|c|c|}
\hline \multirow{2}{*}{$C_{3}:$ Financial stability } & \multicolumn{4}{|c|}{$P_{1}$} & \multicolumn{4}{|c|}{$P_{2}$} & \multicolumn{4}{|c|}{$P_{3}$} \\
\hline & Data & FPP & CFP & MPFP & Data & FPP & CFP & MPFP & Data & FPP & CFP & MPFP \\
\hline$P_{1}$ & & & & & & & & & $4.0-5.0$ & $3.250^{*}$ & $1.301^{*}$ & $2.500^{*}$ \\
\hline$P_{2}$ & $2.0-3.0$ & $1.769^{*}$ & $1.447^{*}$ & 2.000 & & & 1 & & $3.0-5.0$ & $5.750^{*}$ & $1.883^{*}$ & 5.000 \\
\hline$P_{3}$ & & & & & & & & & & & & \\
\hline
\end{tabular}

TABLE 8: Solution matrix of alternatives for $C_{4}$ (Example 1).

\begin{tabular}{|c|c|c|c|c|c|c|c|c|c|c|c|c|}
\hline \multirow{2}{*}{$C_{4}:$ Customer service } & \multicolumn{4}{|c|}{$P_{1}$} & \multicolumn{4}{|c|}{$P_{2}$} & \multicolumn{4}{|c|}{$P_{3}$} \\
\hline & Data & FPP & CFP & MPFP & Data & FPP & CFP & MPFP & Data & FPP & CFP & MPFP \\
\hline$P_{1}$ & & & 1 & & $3.0-6.0$ & $2.913^{*}$ & $1.418^{*}$ & 3.000 & $8.0-13.0$ & $13.302^{*}$ & $3.056^{*}$ & 13.000 \\
\hline$P_{2}$ & & & & & \multirow{2}{*}{\multicolumn{4}{|c|}{1}} & $5.0-9.0$ & $4.566^{*}$ & $2.155^{*}$ & $4.333^{*}$ \\
\hline$P_{3}$ & & & & & & & & & \multicolumn{4}{|c|}{1} \\
\hline
\end{tabular}

Three fuzzy approaches, including the FPP [1], CFP [6], and the proposed MPFP approaches, are illustrated and compared here. Applying the FPP method to this problem yields the weights of criteria $w_{1}=0.504$ (price), $w_{2}=$ 0.259 (quality), $w_{3}=0.163$ (financial stability), and $w_{4}=$ 0.074 (customer service), where the values of all tolerance parameters $d_{k}$ are chosen equal to one. The decision table of the FPP method is listed in Table 3 . The global priorities are $P_{1}=0.352, P_{2}=0.393$, and $P_{3}=0.255$. That is, the priority of partner selection is $P_{2}>P_{1}>P_{3}$. Due to the inconsistency of the interval comparison matrix, some interval ratios are out of the original given ranges. For example, the interval comparison ratio between price $\left(C_{1}\right)$ and quality $\left(C_{2}\right)$ is $[2,3]$, whereas the solution ratio is $w_{1} / w_{2}=0.504 / 0.259=1.946$. The solution ratios of the criteria and the alternatives from the FPP method are listed in Tables 4, 5, 6, 7, and 8, where the values labeled with a star indicate the solutions out of the original given range.

Wang and Chen [6] applied the CFP method to the partnership selection problem, yielding the weights of criteria $w_{1}=0.370, w_{2}=0.276, w_{3}=0.234$, and $w_{4}=0.120$. The decision table for the CFP method is listed in Table 3. The global priorities are $P_{1}=0.342, P_{2}=0.374$, and $P_{3}=0.284$. The priority of partner selection is $P_{2}>P_{1}>P_{3}$. The solution ratios of the criteria and the alternatives by the CFP method are also listed in Tables $4-8$.

In order to compare the results of the FPP, CFP, and MPFP approaches, a triangle type membership function is assumed in the proposed MPFP approach with $r_{i, j, 1}=r_{i, j}$, $r_{i, j, 3}=\overline{r_{i, j}}$, and $r_{i, j, 2}=\left(r_{i, j, 1}+r_{i, j, 3}\right) / 2$. Applying Model 1 to the partnership selection problem yields the weights of criteria $w_{1}=0.506, w_{2}=0.253, w_{3}=0.169$, and $w_{4}=0.072$. The global priorities are $P_{1}=0.347, P_{2}=0.396$, and $P_{3}=0.257$. The priority of partner selection is $P_{2}>P_{1}>P_{3}$. The decision table and the solution ratios by the MPFP method are listed in Tables 3-8.

As listed in Table 3, when three fuzzy preference approaches FPP, CFP, and MPFP are compared, the priority of partner selection for these three approaches is the same; that is, $P_{2}>P_{1}>P_{3}$. The weights of criteria obtained by the proposed MPFP approach are close to those of the FPP approach. The performance of these three methods can be measured by the number of solution ratios out of the given range and the value of the total absolute differences. Take the results of the FPP method in the preference relations matrix of criteria (Table 4) for example. The solution ratio of $r_{1,2}$ is 1.946 , which is out of the decision maker's preference range $[2,3]$. The difference in the solution ratio of this element is $v_{1,2}=2-1.946=0.054$, based on Expression (40). Because the number of solution ratios out of the given range is 1 , the total absolute differences in the solution ratio are 0.054 .

The comparisons of the FPP, CFP, and MPFP approaches are listed in Table 9. As listed in the row of criteria matrix, the number of the solution ratios out of the given ranges is $1,4,0$ and the total absolute differences are $0.054,3.045$, and 0 for FPP, CFP, and MPFP, respectively. In the row of financial stability $\left(C_{3}\right)$, the number of solution ratios out of the preferred ranges is $3,3,1$ and the total absolute differences are 1.731, 4.369, and 1.5. In the row of customer service $\left(C_{4}\right)$, the number of violations is $3,3,1$ and the total absolute differences are $0.823,9.371$, and 0.667 . In these three comparison matrices, the performance of the proposed MPFP method is the best since both the number of solution ratios out of the given ranges and total absolute differences are the least. In the rows of price $\left(C_{1}\right)$ and quality $\left(C_{2}\right)$, because the solution ratios of the FPP and MPFP methods for these two comparison matrices are all located in the preferred ranges, the number of violations and the total absolute differences are 0 . In conclusion, the performance of the proposed MPFP method is the best among these three fuzzy approaches since solution ratios of this approach are closer to the decision maker's preferences than those of the FPP and CFP methods.

Example 2. The second example is a mixed type of pairwise comparison matrix with fuzzy, crisp, and interval preferences as listed in Table 10. Six alternatives $P_{1}, \ldots, P_{6}$ are compared. The decision maker's judgment $r_{1,4}$ is an interval preference with range $[6,8] ; r_{5,4}$ is a crisp preference with value $7 ; r_{6,2}$ is unknown; the rest of the judgments are fuzzy preferences; that is, the pairwise comparison matrix is incomplete, which 
TABLE 9: Comparisons of FPP, CFP, and MFP methods (Example 1).

\begin{tabular}{|c|c|c|c|c|c|c|}
\hline \multirow{2}{*}{ Matrix } & \multicolumn{2}{|c|}{ FPP } & \multicolumn{2}{|c|}{ CFP } & \multicolumn{2}{|c|}{ MPFP } \\
\hline & No. & $\begin{array}{c}\text { Total } \\
\text { difference }\end{array}$ & No. & $\begin{array}{c}\text { Total } \\
\text { difference }\end{array}$ & No. & $\begin{array}{c}\text { Total } \\
\text { difference }\end{array}$ \\
\hline Criteria matrix (Table 4) & 1 & 0.054 & 4 & 3.045 & 0 & 0 \\
\hline$C_{1}:$ Price (Table 5) & 0 & 0 & 2 & 0.146 & 0 & 0 \\
\hline$C_{2}:$ Quality (Table 6) & 0 & 0 & 3 & 0.438 & 0 & 0 \\
\hline$C_{3}:$ Financial stability (Table 7) & 3 & 1.731 & 3 & 4.369 & 1 & 1.5 \\
\hline $\mathrm{C}_{4}:$ Customer service (Table 8) & 3 & 0.823 & 3 & 9.371 & 1 & 0.667 \\
\hline
\end{tabular}

contains 1 interval preference, 1 crisp preference, and 12 fuzzy preferences.

Applying Yu's approach to this example yields the weights of alternatives $w_{1}=0.4, w_{2}=0.1, w_{3}=0.05, w_{4}=0.05$, $w_{5}=0.3$, and $w_{6}=0.1$, where $M^{1}=2.639, M^{0}=0.560$, and $\alpha=5.772$. The objective values Obj1 $=0.56$ and Obj $2=6$. The solution matrix of alternatives is listed in Table 11. The number of solution ratios out of the given range is $2: r_{1,5}=$ 1.33 out of given fuzzy preference $(2,3,4) ; r_{1,4}=6$ out of given crisp value 7 . The total absolute difference in solution ratio is 1.67. Since Obj2 indicates the degree of fulfillment of the decision maker's preferences, the average degree of fulfillment can be measured as $6 / 12=0.5$. It should be pointed out that the denominator is 12 instead of 14 because the degree of fulfillment for crisp and interval preferences is not taken into account in Yu's approach.

Applying the proposed MPMP approach (Model 5) to this example yields $b_{1,4,0}=1, b_{5,4,0}=1$, Obj $1=0.56$, and Obj $2=$ 7.778 , given $\alpha=1,000,000$. The weights of alternatives $w_{1}=$ $0.375, w_{2}=0.094, w_{3}=0.047, w_{4}=0.047, w_{5}=0.328$, and $w_{6}=0.109$. The solution matrix of alternatives is listed in Table 12 where $r_{1,5}=1.14$ is out of given fuzzy preference $(2,3,4)$. The number of solution ratios out of the given range is 1 . The total absolute difference in solution ratio is 0.86 . The average degree of fulfillment is 7.778/14 $=0.556$.

As shown in Example 2, the performance of the proposed approach is better than that of Yu's approach since the former has less number of solution ratios out of the given range (1 versus 2 ), fewer total absolute differences (0.86 versus 1.67$)$, and a higher average degree of fulfillment (0.556 versus 0.5$)$.

Example 3. In order to demonstrate the capability of the proposed approach in treating step preferences, a three-step preference $r_{6,2}=[2,3,4,5: 0.8,1,0.5]$ is added into example 2 as Example 3. Applying Model 5 to this Example yields $b_{1,4,0}=1, b_{5,4,0}=1, b_{6,2,0}=0, b_{6,2,1}=0$, Obj1 $=0.847$, and Obj2 $=6.795$. The weights of alternatives $w_{1}=0.364$, $w_{2}=0.091, w_{3}=0.045, w_{4}=0.045, w_{5}=0.318$, and $w_{6}=$ 0.136 . The solution matrix of alternatives is listed in Table 13 . The number of solution ratios out of the given range is 2 with $r_{1,5}=1.14$ out of given fuzzy preference $(2,3,4)$ and $r_{6,2}=1.5$ out of given step preference $[2,3,4,5: 0.8,1,0.5]$. The total absolute difference in solution ratio is 1.36 . The average degree of fulfillment is $6.795 / 15=0.453$. Because this example
TABLE 10: Pairwise comparisons of alternatives with mixed preferences (Example 2).

\begin{tabular}{|c|c|c|c|c|c|}
\hline$P_{1}$ & $P_{2}$ & $P_{3}$ & $P_{4}$ & $P_{5}$ & $P_{6}$ \\
\hline$P_{1}$ & $(3,4,5)$ & $(5,6,8)$ & {$[6,8]$} & $(2,3,4)$ & $(2,4,5)$ \\
\hline$P_{2}$ & & $(2,3,6)$ & $(1,2,4)$ & & \\
\hline \multicolumn{6}{|l|}{$P_{3}$} \\
\hline$P_{4}$ & & $(1,2,5)$ & & & \\
\hline$P_{5}$ & $(3,4,6)$ & $(5,6,8)$ & 7 & & $(2,3,4)$ \\
\hline$P_{6}$ & - & $(2,3,6)$ & $(1,2,3)$ & & \\
\hline
\end{tabular}

TABLE 11: Solution matrix of alternatives by Yu's approach (Example 2).

\begin{tabular}{ccccccc}
\hline & $P_{1}$ & $P_{2}$ & $P_{3}$ & $P_{4}$ & $P_{5}$ & $P_{6}$ \\
\hline$P_{1}$ & 1.00 & 4.00 & 8.00 & 8.00 & $1.33^{*}$ & 4.00 \\
$P_{2}$ & 0.25 & 1.00 & 2.00 & 2.00 & 0.33 & 1.00 \\
$P_{3}$ & 0.13 & 0.50 & 1.00 & 1.00 & 0.17 & 0.50 \\
$P_{4}$ & 0.13 & 0.50 & 1.00 & 1.00 & 0.17 & 0.50 \\
$P_{5}$ & 0.75 & 3.00 & 6.00 & $6^{*}$ & 1.00 & 3.00 \\
$P_{6}$ & 0.25 & 1.00 & 2.00 & 2.00 & 0.33 & 1.00 \\
\hline
\end{tabular}

includes a step preference, the FPP, CFP, and Yu's approaches cannot solve this problem.

\section{Conclusions}

This study proposes a general model based on mixed integer programming and GP-AHP to solve partnership selection problems with various types of preferences. In order to aggregate different types of preferences, the objective functions of all models in this study are designed in a similar way compatible with fuzzy preferences. The degree of fulfillment of a decision maker's preferences is also taken into account. The proposed approach can deal with crisp, interval, fuzzy, step, or mixed comparison matrices, derive crisp priorities, and improve multiple solution problems.

Compared with Yu's approach [17], the proposed approach can treat problems with step preferences, keep more solution ratios within the given preferred intervals, and yield less deviation. Yu's slope-based approach cannot treat problems involving step preferences because the slopes of some line segments for step preferences cannot be 
TABLE 12: Solution matrix of alternatives by the proposed approach (Example 2).

\begin{tabular}{ccccccc}
\hline & $P_{1}$ & $P_{2}$ & $P_{3}$ & $P_{4}$ & $P_{5}$ & $P_{6}$ \\
\hline$P_{1}$ & 1.00 & 4.00 & 8.00 & 8.00 & $1.14^{*}$ & 3.43 \\
$P_{2}$ & 0.25 & 1.00 & 2.00 & 2.00 & 0.29 & 0.86 \\
$P_{3}$ & 0.13 & 0.50 & 1.00 & 1.00 & 0.14 & 0.43 \\
$P_{4}$ & 0.13 & 0.50 & 1.00 & 1.00 & 0.14 & 0.43 \\
$P_{5}$ & 0.87 & 3.50 & 7.00 & 7.00 & 1.00 & 3.00 \\
$P_{6}$ & 0.29 & 1.17 & 2.33 & 2.33 & 0.33 & 1.00 \\
\hline
\end{tabular}

TABLE 13: Solution matrix of alternatives by the proposed approach (Example 3).

\begin{tabular}{ccccccc}
\hline & $P_{1}$ & $P_{2}$ & $P_{3}$ & $P_{4}$ & $P_{5}$ & $P_{6}$ \\
\hline$P_{1}$ & 1.00 & 4.00 & 8.00 & 8.00 & $1.14^{*}$ & 2.67 \\
$P_{2}$ & 0.25 & 1.00 & 2.00 & 2.00 & 0.29 & 0.67 \\
$P_{3}$ & 0.13 & 0.50 & 1.00 & 1.00 & 0.14 & 0.33 \\
$P_{4}$ & 0.13 & 0.50 & 1.00 & 1.00 & 0.14 & 0.33 \\
$P_{5}$ & 0.88 & 3.50 & 7.00 & 7.00 & 1.00 & 2.33 \\
$P_{6}$ & 0.38 & $1.50^{*}$ & 3.00 & 3.00 & 0.43 & 1.00 \\
\hline
\end{tabular}

obtained. The proposed approach based on mixed integer programming employs binary variables rather than slopes to solve problems with interval, step, and crisp preferences without calculating slopes. Compared with FPP approach [1], the proposed approach can improve multiple solutions problems, deal with step preferences, and release the requirement for prespecified tolerance parameters.

In addition, the proposed approach can treat incomplete preference matrices with flexibility in reducing the number of pairwise comparisons required and can also be conveniently developed into a decision support system. In future studies, determining how to incorporate more types of uncertain preferences and provide visual aids for decision makers can be addressed.

\section{Acknowledgment}

This research is supported by the National Science Council of the Republic of China under Contract NSC 98-2410-H-239003.

\section{References}

[1] L. Mikhailov, "Fuzzy analytical approach to partnership selection in formation of virtual enterprises," Omega, vol. 30, no. 5, pp. 393-401, 2002.

[2] T. L. Saaty, "A scaling method for priorities in hierarchical structures," Journal of Mathematical Psychology, vol. 15, no. 3, pp. 234-281, 1977.

[3] R. G. Kasilingam and C. P. Lee, "Selection of vendors-a mixedinteger programming approach," Computers and Industrial Engineering, vol. 31, no. 1-2, pp. 347-350, 1996.

[4] M. C. Y. Tam and V. M. R. Tummala, "An application of the AHP in vendor selection of a telecommunications system," Omega, vol. 29, no. 2, pp. 171-182, 2001.
[5] E. Herrera-Viedma, F. Herrera, F. Chiclana, and M. Luque, "Some issues on consistency of fuzzy preference relations," European Journal of Operational Research, vol. 154, no. 1, pp. 98109, 2004.

[6] T.-C. Wang and Y.-H. Chen, "Applying consistent fuzzy preference relations to partnership selection," Omega, vol. 35 , no. 4, pp. 384-388, 2007.

[7] T. L. Saaty and L. G. Vargas, "Uncertainty and rank order in the analytic hierarchy process," European Journal of Operational Research, vol. 32, no. 1, pp. 107-117, 1987.

[8] F. Torfi, R. Z. Farahani, and S. Rezapour, "Fuzzy AHP to determine the relative weights of evaluation criteria and Fuzzy TOPSIS to rank the alternatives," Applied Soft Computing Journal, vol. 10, no. 2, pp. 520-528, 2010.

[9] Z. Xu and C. Wei, "A Consistency improving method in the analytic hierarchy process," European Journal of Operational Research, vol. 116, no. 2, pp. 443-449, 1999.

[10] H.-L. Li and L.-C. Ma, "Detecting and adjusting ordinal and cardinal inconsistencies through a graphical and optimal approach in AHP models," Computers and Operations Research, vol. 34, no. 3, pp. 780-798, 2007.

[11] J. Zeng, M. An, and N. J. Smith, "Application of a fuzzy based decision making methodology to construction project risk assessment," International Journal of Project Management, vol. 25, no. 6, pp. 589-600, 2007.

[12] Y.-M. Wang and K.-S. Chin, "A linear goal programming priority method for fuzzy analytic hierarchy process and its applications in new product screening," International Journal of Approximate Reasoning, vol. 49, no. 2, pp. 451-465, 2008.

[13] C. Kahraman and I. Kaya, "A fuzzy multicriteria methodology for selection among energy alternatives," Expert Systems with Applications, vol. 37, no. 9, pp. 6270-6281, 2010.

[14] H.-F. Lin, "An application of fuzzy AHP for evaluating course website quality," Computers and Education, vol. 54, no. 4, pp. 877-888, 2010.

[15] W. D. Cook, B. Golany, M. Kress, M. Penn, and T. Raviv, "Optimal allocation of proposals to reviewers to facilitate effective ranking," Management Science, vol. 51, no. 4, pp. 655661, 2005.

[16] H. J. Zimmermann, "Description and optimization of fuzzy systems," International Journal of General Systems, vol. 2, no. 4, pp. 209-215, 1976.

[17] C.-S. Yu, "A GP-AHP method for solving group decisionmaking fuzzy AHP problems," Computers and Operations Research, vol. 29, no. 14, pp. 1969-2001, 2002.

[18] W. W. Cooper, "Origins, uses of, and relationships between multi-objective programming and data envelopment analysis," Journal of Multi-Criteria Decision Analysis, vol. 13, no. 1, pp. 311, 2005.

[19] H. A. Taha, Operations Research, Prentice Hall, Upper Saddle River, NJ, USA, 2003.

[20] L.-C. Ma and H.-L. Li, "A fuzzy ranking method with range reduction techniques," European Journal of Operational Research, vol. 184, no. 3, pp. 1032-1043, 2008. 


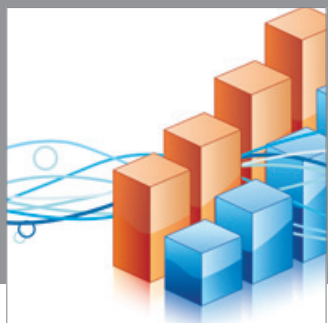

Advances in

Operations Research

mansans

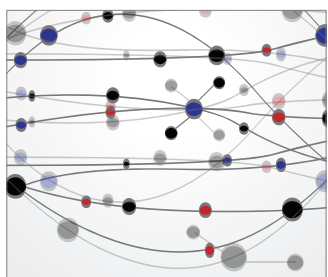

The Scientific World Journal
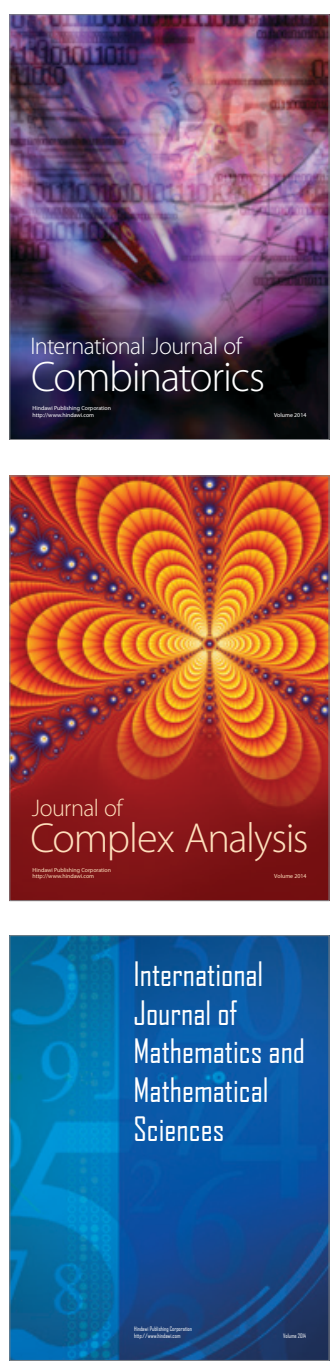
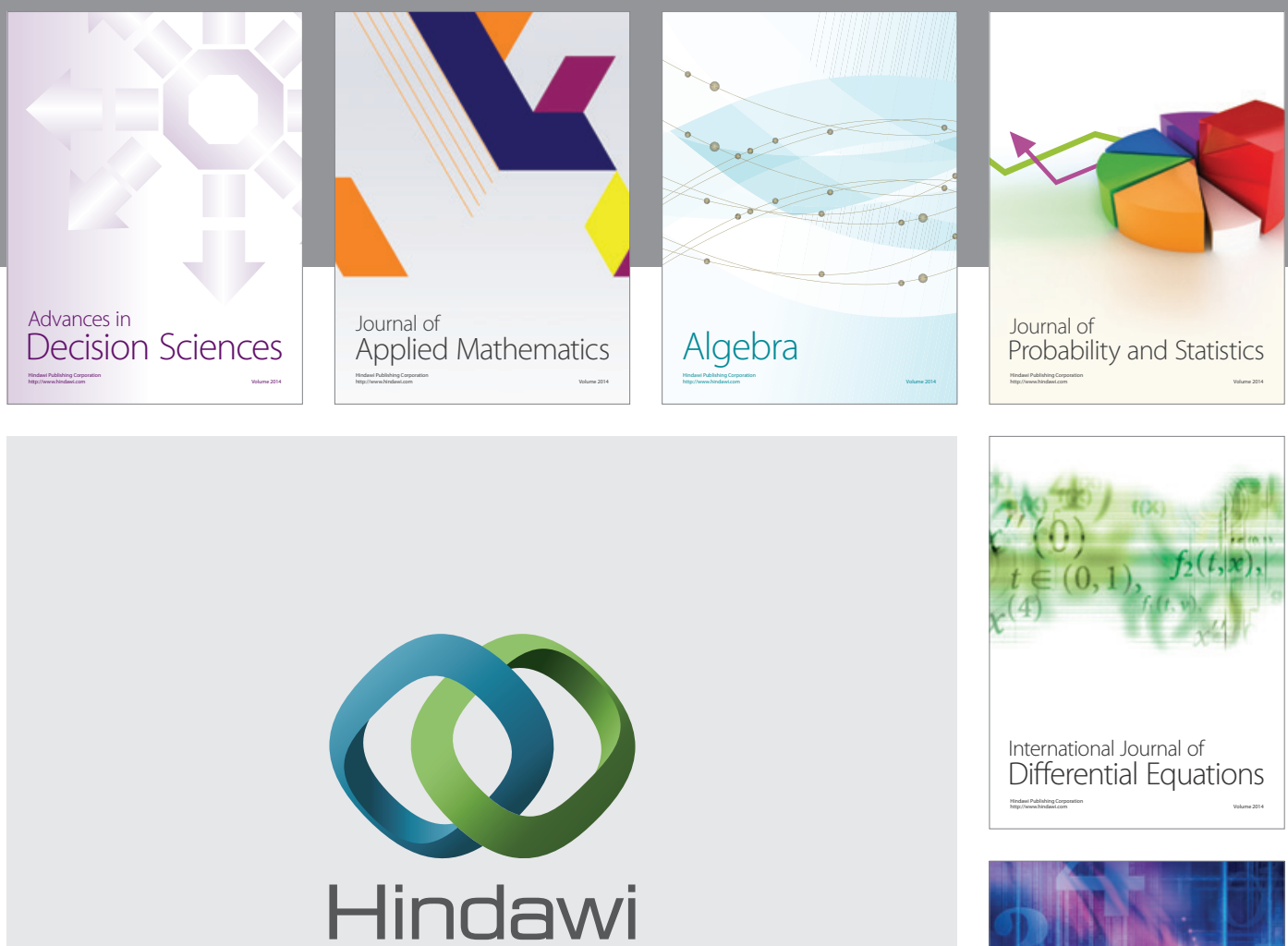

Submit your manuscripts at http://www.hindawi.com
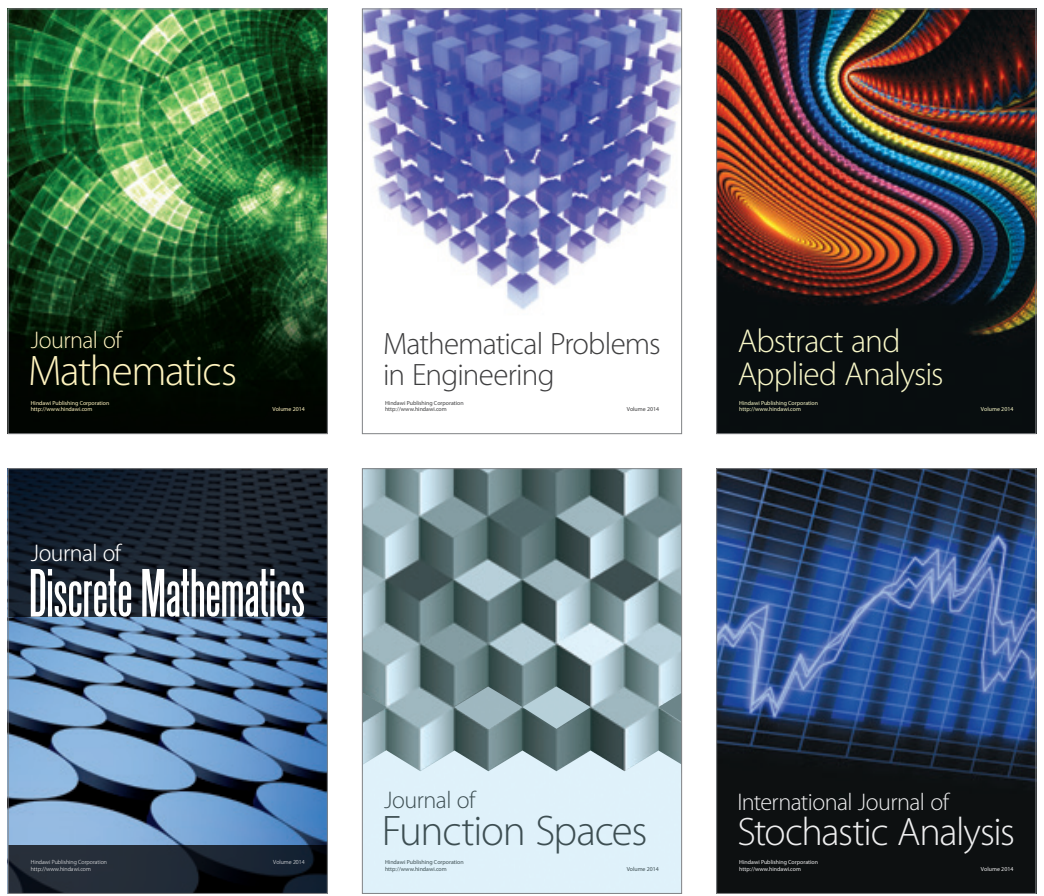

Journal of

Function Spaces

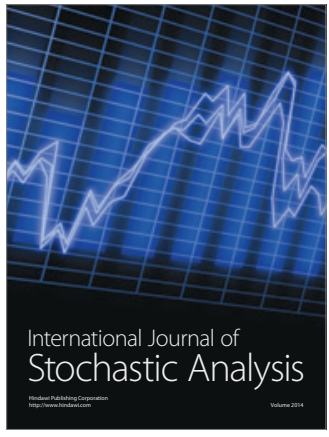

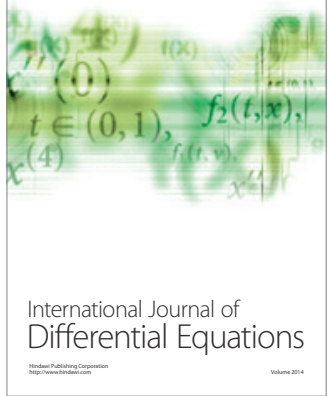
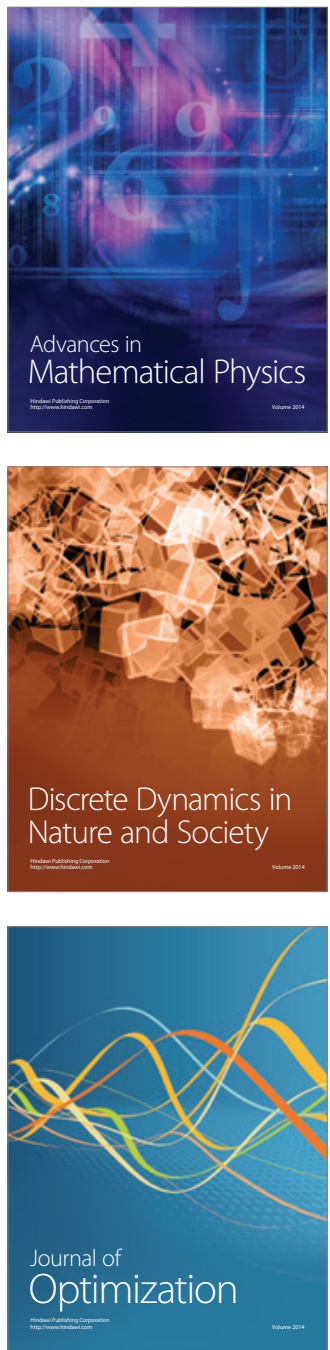